University of Nebraska - Lincoln

DigitalCommons@University of Nebraska - Lincoln

March 1991

\title{
Synthesis and superconducting properties of $\mathrm{TI}-\mathrm{Ba}-\mathrm{Ca}-\mathrm{Cu}-\mathrm{O}$ films
}

\author{
Sy_Hwang Liou \\ University of Nebraska-Lincoln, sliou@unl.edu \\ V.K. Chan \\ University of Nebraska - Lincoln \\ F. Foong \\ University of Nebraska - Lincoln \\ W.Y. Lee \\ University of Nebraska - Lincoln \\ Y.S. Gou \\ University of Nebraska - Lincoln \\ See next page for additional authors
}

Follow this and additional works at: https://digitalcommons.unl.edu/physicsliou

Part of the Physics Commons

Liou, Sy_Hwang; Chan, V.K.; Foong, F.; Lee, W.Y.; Gou, Y.S.; and Uen, T.M., "Synthesis and superconducting properties of TI-Ba-Ca-Cu-O films" (1991). Si-Hwang Liou Publications. 49.

https://digitalcommons.unl.edu/physicsliou/49

This Article is brought to you for free and open access by the Research Papers in Physics and Astronomy at DigitalCommons@University of Nebraska - Lincoln. It has been accepted for inclusion in Si-Hwang Liou Publications by an authorized administrator of DigitalCommons@University of Nebraska - Lincoln. 
Authors

Sy_Hwang Liou, V.K. Chan, F. Foong, W.Y. Lee, Y.S. Gou, and T.M. Uen 


\title{
SYNTHESIS AND SUPERCONDUCTING PROPERTIES OF Tl-Ba-Ca-Cu-O FILMS
}

\author{
S.H. Liou, V.K. Chan, F. Foong \\ Behlen Laboratory of Physics and Center for Materials Research and Analysis \\ University of Nebraska, Lincoln, Nebraska 68588-0111 \\ W.Y. Lee \\ IBM Almaden Research Center \\ San Jose, California 95120-6099 \\ Y.S. Gou and T.M. Uen \\ Institute of Electrophysics \\ National Chiao Tung University, Hsinchu, Taiwan
}

\begin{abstract}
The Tl-Ba-Ca-Cu-O superconducting films were synthesized by sputtering either from a single target or from two oxide targets in a symmetric configuration. Films with zero resistance $\mathrm{T}_{\mathrm{c}}$ of up to $122 \mathrm{~K}$ were obtained after various post annealing treatment at $870-950^{\circ} \mathrm{C}$ under oxygen atmosphere. We have studied morphology, structure, magnetic and superconducting properties of these films. Films prepared by two different sputtering techniques have similar results which depend mostly on the film compositions and their annealing conditions. We found that the induced magnetic flux in the film decreases rapidly with increasing temperature, indicating the weak flux pinning.
\end{abstract}

\section{Introduction}

Following the initial discovery of superconductivity in the $\mathrm{Tl}-$ Ba-Ca-Cu-O system, ${ }^{1,2}$ the highest $\mathrm{T}_{\mathrm{c}}(\mathrm{R}=0)$ at $125 \mathrm{~K}$ has been observed in the compound of $\mathrm{Tl}_{2} \mathrm{Ba}_{2} \mathrm{Ca}_{2} \mathrm{Cu}_{3} \mathrm{O}_{10}(2223)^{3,4}$. Thin film research on the Tl-based superconductors is particularly important because their $\mathrm{T}_{c}$ 's $(\mathrm{R}=0)$ are much higher than those of the rare earth based $\mathrm{Y}_{1} \mathrm{Ba}_{2} \mathrm{Cu}_{3} \mathrm{O}_{7-\mathrm{x}}$ compounds. Furthermore, it is likely to obtain more stable high critical current densities in excess of $10^{5}-10^{6} \mathrm{~A} / \mathrm{cm}^{2}$ at $77 \mathrm{~K}$ in the Tl-based system.

Recently, polycrystalline films $0.7 \mu \mathrm{m}$ thick containing predominantly $\mathrm{Tl}_{2} \mathrm{Ba}_{2} \mathrm{Ca}_{1} \mathrm{Cu}_{2} \mathrm{O}_{8}$ (2212) phase with $\mathrm{T}_{c}(\mathrm{R}=0)$ at $97 \mathrm{~K}$ and a transport $\mathrm{J}_{c}$ of $1.1 \times 10^{5} \mathrm{~A} / \mathrm{cm}^{2}$ at $76 \mathrm{~K}$ have been obtained by Ginley et al. ${ }^{5}$ using electron beam evaporation. Highly oriented films $0.4 \mu \mathrm{m}$ thick (with the c-axis perpendicular to the film plane) containing nearly a single phase of 2212 as well as having a $T_{c}(R=0)$ at $102 \mathrm{~K}$ and a transport $J_{c}$ of $1.2 \times 10^{5} \mathrm{~A} / \mathrm{cm}^{2}$ at $77 \mathrm{~K}$ have been prepared by Ichikawa et al. ${ }^{6}$ using RF magnetron sputtering and a single oxide target. Highly textured c-axis oriented films $2.0-4.0 \mu \mathrm{m}$ thick containing both 2223 and 2212 phases with a $\mathrm{T}_{\mathrm{c}}(\mathrm{R}=0)$ at $120 \mathrm{~K}$ and a $\mathrm{J}_{\mathrm{c}}$ by magnetic measurement of $1.5 \times 10^{4} \mathrm{~A} / \mathrm{cm}^{2}$ at $77 \mathrm{~K}$ have been reported by Lee et al. ${ }^{7}$ using two identical oxide targets in a symmetrical RF diode sputtering system.

The ability to produce thin films with the pure high $T_{c}$ $\mathrm{Tl}_{2} \mathrm{Ba}_{2} \mathrm{Ca}_{2} \mathrm{Cu}_{3} \mathrm{O}_{10}$ phase not only can further improve $\mathrm{J}_{c}$ 's at higher temperatures but may also provide a useful material for

Manuscript received September 24, 1990. a fundamental study on the Tl-based superconducting oxides. In this paper, we discuss the preparation conditions for films with $\mathrm{T}_{\mathrm{c}}(\mathrm{R}=0)$ at $122 \mathrm{~K}$. The results of magnetic properties of these films are presented.

\section{Film Growth}

The Tl-Ba-Ca-Cu-O films were prepared on $\mathrm{MgO}(100), \mathrm{Y}-\mathrm{ZrO}_{2}$ (random orientation) and $\mathrm{LaAlO}_{3}(100)$ substrates by sputtering either from a single targets or from two oxide target in a symmetric configuration. The details of the sample synthesis have been reported in our previous papers ${ }^{7,8}$. Due to the volatility of the Tl-oxide, the optimal processing of the Tl-based films requires good control of the Tl-vapor partial pressure. We have used two different methods to control the Tl-vapor partial pressure. One is annealing the film in a sealed gold box with a composite Tl-compound. The other one is annealing the film in a two zone-furnace, in which the $\mathrm{Tl}$-vapor partial pressure is controlled by the zone temperature. The first method is much simpler and the results are reproducible. The second method requires a fine adjustment which we need to study further. The films reported here were prepared by the first method. The annealing steps have been shown to be a crucial determinant of the quality of Tl-based superconducting films ${ }^{9}$. In this study, we show that the films consist of nearly pure $\mathrm{Tl}_{2} \mathrm{Ba}_{2} \mathrm{Ca}_{2} \mathrm{Cu}_{3} \mathrm{O}_{10}$ phase with $\mathrm{T}_{\mathrm{c}}(\mathrm{R}=0)$ in the range of $100 \mathrm{~K}$ to $122 \mathrm{~K}$ and $\mathrm{c}$-axis perpendicular to the film plane were obtain after annealing $870 \sim 895$ for up to 3 hours. The major factors that lead to achieve a higher $T_{c}$ than that of the previous study are perhaps due to the better control of Tl-vapor partial pressure and annealing at higher temperature for a longer time. We also observed a substantial improvement in the superconducting properties for films subsequently annealed at low temperature $\left(<700^{\circ} \mathrm{C}\right)$ either in air or oxygen. The detailed study of low temperature annealing will be discussed elsewhere ${ }^{10}$.

\section{Composition, Structure and Processing Conditions}

The film compositions were determined by $\mathrm{x}$-ray fluorescence microprobe spectroscopy. A typical composition of as-deposited films is $\mathrm{Tl}_{2.1} \mathrm{Ba}_{2.4} \mathrm{Ca}_{2.0} \mathrm{Cu}_{3.1} \mathrm{O}_{\mathrm{x}}$. The composition of the asdeposited film was very homogeneous, but the composition of 
the post-annealed film was not homogeneous, especially the $\mathrm{Tl}$ and $\mathrm{Ca}$ content. As an example, we have tested the stability of $\mathrm{Tl}$ in a single crystal. As shown in Figure 1(a), a single crystal with 2223 phase was prepared on a $\mathrm{MgO}(100)$ substrate. After we had annealed this crystal at $800^{\circ} \mathrm{C}$ without providing additional $\mathrm{Tl}$-vapor for 15 minute, we found that the phase of this crystal was changed, its surface became rough, and its Tl-content was lost completely. Its morphology, as shown in Figure 1(b), is completely different from the original crystal. The $\mathrm{Tl}$ content can vary widely depending on the annealing temperature and the duration of the annealing time at the high temperature. The amount of $\mathrm{Ba}, \mathrm{Ca}$ and $\mathrm{Cu}$ in the annealed films was found to be insensitive to the processing conditions if we average over a large area. However, the micro-scale composition of annealed films has some variations which depend on the processing conditions. In order to investigate the effect of the processing conditions on the micro-scale composition, we have prepared two films with similar superconducting and structural properties. The morphology and the composition of
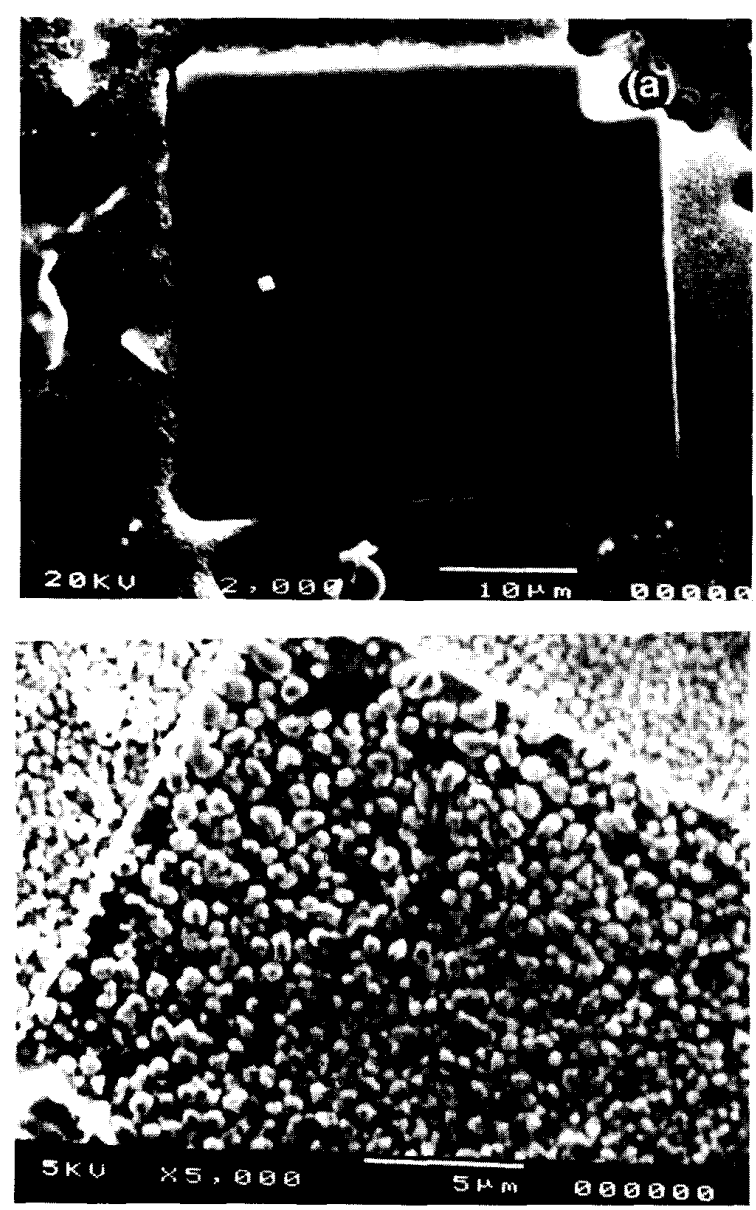

Fig. 1 Scanning electron micrographs of Tl-Ba-Ca-Cu-O film on $\mathrm{MgO}(100)$ (a) a single crystal with 2223 phase, (b) after annealed at $800^{\circ} \mathrm{C}$ without additional Tl-vapor in the gold box.

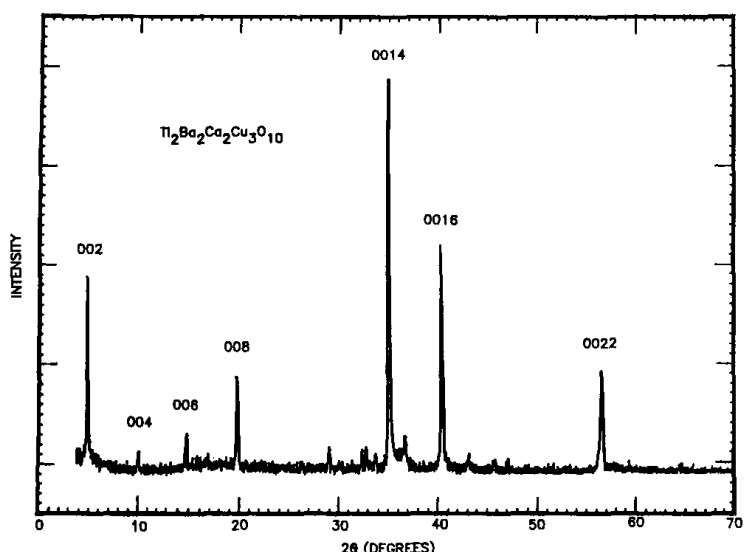

Fig. 2 X-ray $(\theta-2 \theta$ scans normal to the film plane for a Tl-Ba$\mathrm{Ca}-\mathrm{Cu}-\mathrm{O}$ film containing primarily the 2223 phase. The film is grown on a $\mathrm{Y}-\mathrm{ZrO}_{2}$ substrate. (The $\mathrm{Y}-\mathrm{ZrO}_{2}$ single crystal substrate is cut randomly and is not along (100) orientation).

the films were studied by scanning electron microscope with energy dispersive $\mathrm{x}$-ray analysis. These films are highly c-axis oriented with mostly $(00 \ell)$ peaks of $\mathrm{Tl}_{2} \mathrm{Ba}_{2} \mathrm{Ca}_{2} \mathrm{Cu}_{3} \mathrm{O}_{10}$ phase as revealed by the $\mathrm{x}$-ray diffraction pattern (as shown in Figure 2). The micrographs of films on $\mathrm{Y}_{-} \mathrm{ZrO}_{2}$ substrates after annealing at $890^{\circ} \mathrm{C}$ for 3 hours and at $895^{\circ} \mathrm{C}$ for 1 hour are shown in Figures 3(a) and 3(b) respectively. The films annealed at $890^{\circ} \mathrm{C}$ for 3 hours had plate-like grains with many small Carich grains on their surface. The film composition at different portions is marked in Figure 3(a) and is listed in Table I.

Table I. The film composition at various portions
A. Plate-like
B. Plate-like
$\mathrm{Tl}_{1.6} \mathrm{Ba}_{1.7} \mathrm{Ca}_{2.0} \mathrm{Cu}_{3.0} \mathrm{O}_{\mathrm{x}}$
C. Dot
$\mathrm{Tl}_{1.5} \mathrm{Ba}_{1.7} \mathrm{Ca}_{2.0} \mathrm{Cu}_{3.0} \mathrm{O}_{x}$
D. Dot
E. Rod-like
$\mathrm{Tl}_{1.3} \mathrm{Ba}_{1.9} \mathrm{Ca}_{4.4} \mathrm{Cu}_{3.0} \mathrm{O}_{\mathrm{x}}$
$\mathrm{Tl}_{2.0} \mathrm{Ba}_{3.0} \mathrm{Ca}_{1.1} \mathrm{Cu}_{3.0} \mathrm{O}_{\mathrm{x}}$

The morphology of the film annealed at $895^{\circ} \mathrm{C}$ for 1 hour is shown in Figure 3(b). The plate-like grains were connected much closer than that of the previous film. The composition of this film is $\mathrm{Tl}_{1.8} \mathrm{Ba}_{1.8} \mathrm{Ca}_{1.8} \mathrm{Cu}_{3.0} \mathrm{O}_{\mathrm{x}}$ and it does not change from place to place. However, we still observe many submicron Carich dots in the plate-like grains.

\section{Transport, Flux Trapping, and Granularity}

The superconducting and transport properties were measured by the standard four-point measurement using a dc method by switching the polarization of the applied current during the measurement. Critical current densities ( $\mathrm{J}_{c}$ 's) were measured in the van der pauw configuration with and without a lithographic patterning. Figure 4 shows the data of resistance versus temperature of the film annealed at $895^{\circ} \mathrm{C}$ for 1 hour. This 

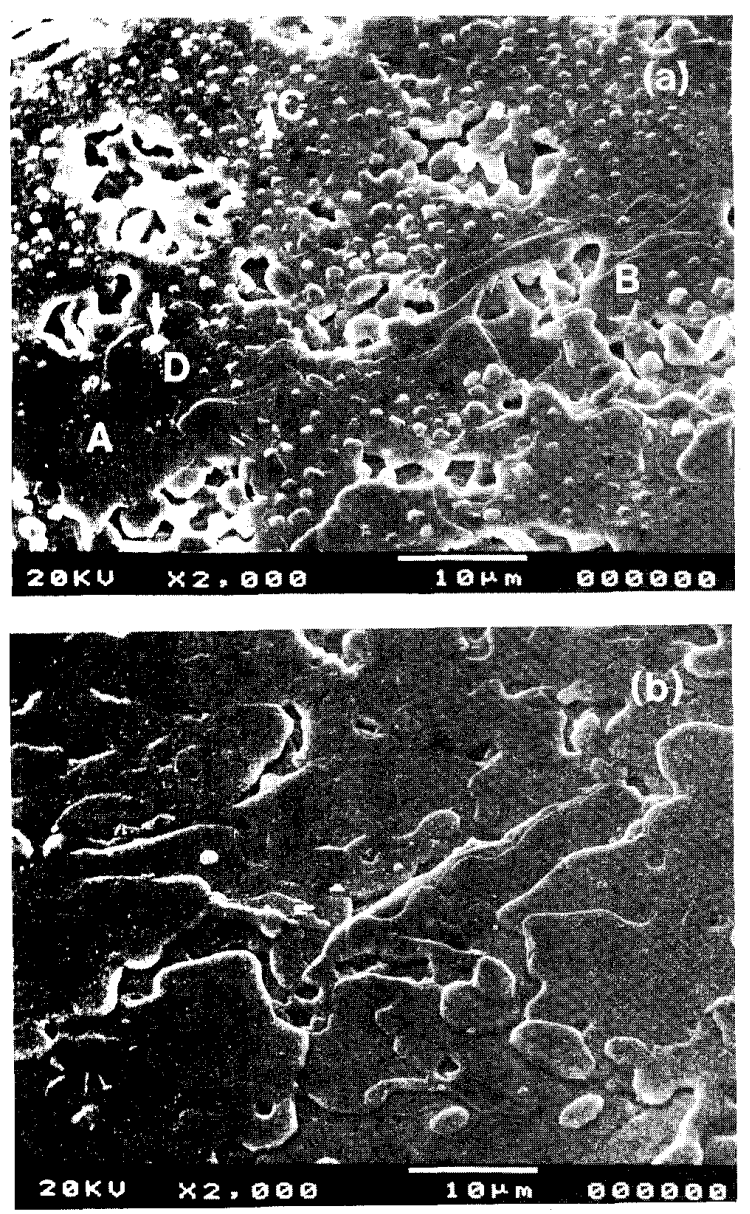

Fig. 3 Scanning electron micrographs of Tl-Ba-Ca-Cu-O films on $\mathrm{Y}-\mathrm{ZrO}_{2}$. (a) annealed at $890^{\circ} \mathrm{C}$ for 3 hours, (The composition of marked portions are listed in Table I.) (b) annealed at $895^{\circ} \mathrm{C}$ for 1 hour. (The white dots are the Ca-rich portions.)

film have a $T_{c}$ onset at $130 \mathrm{~K}$ and a $\mathrm{T}_{c}(\mathrm{R}=0)$ at $122 \mathrm{~K}$. The $\mathrm{J}_{c}$ 's at zero magnetic field is about $10^{4} \mathrm{~A} / \mathrm{cm}^{2}$.

We found the superconducting transition temperature of our films with $\mathrm{Tl}_{2} \mathrm{Ba}_{2} \mathrm{Ca}_{2} \mathrm{Cu}_{3} \mathrm{O}_{10}$ phase vary from $100 \mathrm{~K}$ to $122 \mathrm{~K}$, and it is very sensitive to the processing conditions. The $\mathrm{J}_{\mathrm{c}}$ 's of the films prepared on $\mathrm{Y}-\mathrm{ZrO}_{2}$ and $\mathrm{MgO}$ substrates were in the range of $10^{3} \sim 10^{4} \mathrm{~A} / \mathrm{cm}^{2}$ at $77 \mathrm{~K}$. The $J_{c}$ 's of the films prepared on $\mathrm{SrTiO}_{3}$ and $\mathrm{LaAlO}_{3}$ substrates were in the range of $10^{4} \mathrm{~A} / \mathrm{cm}^{2} \sim 10^{6} \mathrm{~A} / \mathrm{cm}^{2}$ at $77 \mathrm{~K}$.

The magnetic properties of the films were studied by using SQUID magnetometer. The diamagnetic shielding and Meissner effect data were shown in Figure 5 . The diamagnetic shielding lata was obtained after cooling in zero field, followed by applying a field of 20 Oe and taking data on warming. The Mrissner effect data was measured on cooling in an applied field of $20 \mathrm{Oe}$. The diamagnetic shielding and Meissner signals

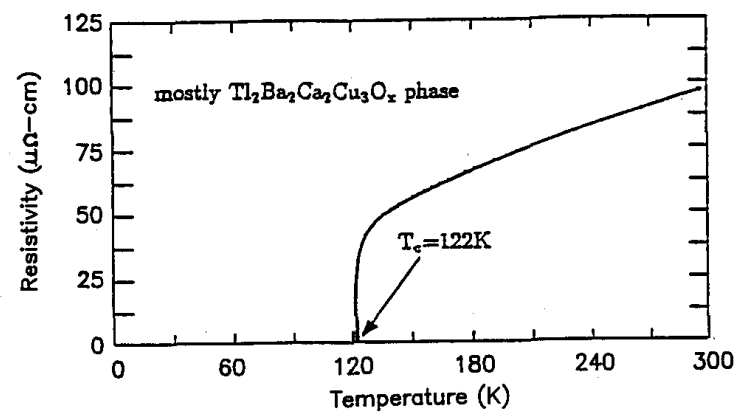

Fig. 4 A typical Resistance vs. temperature curve of the TIbased superconducting film annealed at $895^{\circ} \mathrm{C}$ for 1 hour under $\mathrm{O}_{2}$.

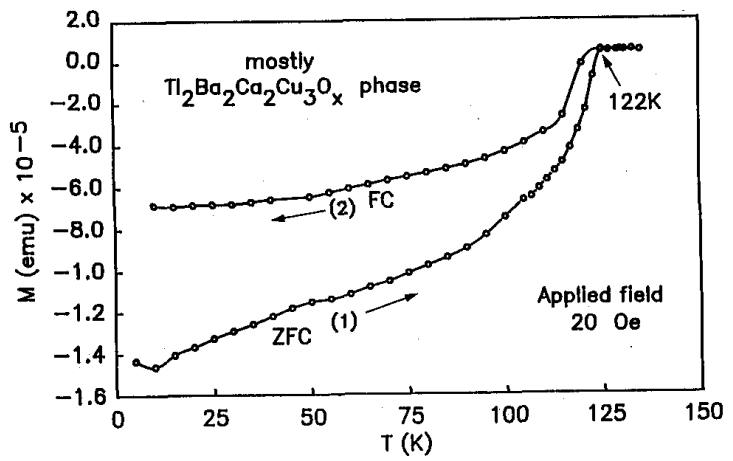

Fig. 5 The diamagnetic shielding effect (ZFC) and the Meissner effect (FC) of the Tl-based superconducting film annealed at $895^{\circ} \mathrm{C}$ for 1 hour under $\mathrm{O}_{2}$.

at $6 \mathrm{~K}$ are estimated to be $30 \%$ and $15 \%$ of those for a perfect diamagnetic of the same shape and volume, respectively. The low values of the diamagnetic shielding and the Meissner signals indicate a serious film-substrate interactions or a substantial portion of non-superconductor in the film.

Figure 6 shows a magnetization curve at $6 \mathrm{~K}$ for the film annealed at $895^{\circ} \mathrm{C}$, the applied fields were up to $\pm 55 \mathrm{kOe}$ and were perpendicular to the films' surface. Analysis of these data using the standard Bean method indicates a critical current density of $7.5 \times 10^{4} \mathrm{~A} / \mathrm{cm}^{2}$ at $6 \mathrm{~K}$ under $55 \mathrm{kOe}^{11}$. $\mathrm{J}_{\mathrm{c}}$ of $7.5 \mathrm{x}$ $10^{5} \mathrm{~A} / \mathrm{cm}^{2}$ at $6 \mathrm{~K}$ and $4.2 \times 10^{4} \mathrm{~A} / \mathrm{cm}^{2}$ at $77 \mathrm{~K}$ under zero field were obtained for this film. The flux trapping data, as shown in Figure 7, was obtained after cooling in the applied field. The induced flux in the film decrease rapidly with increasing temperature. This clearly indicates the weak flux pinning at higher temperature. The flux trapping data correspond to the $J_{c}$ function of temperature at zero field. This rapid decrease in $\mathrm{J}_{\mathrm{c}}$, which is similar to that of some $\mathrm{YBa}_{2} \mathrm{Cu}_{3} \mathrm{O}_{7-\mathrm{x}}$ granular films, may be due to the granular nature of these films ${ }^{12}$. 


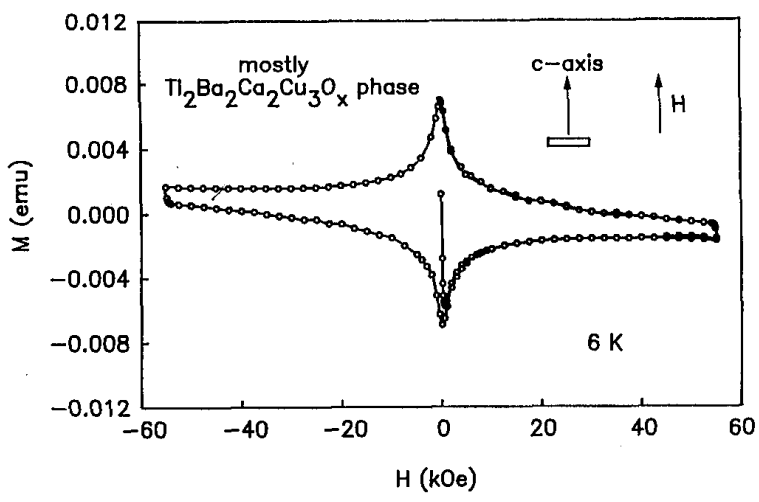

Fig. 6 Magnetization versus field curve at $6 \mathrm{~K}$ for the film annealed at $895^{\circ} \mathrm{C}$ for 1 hour. The magnetic field was applied normal to the film surface.

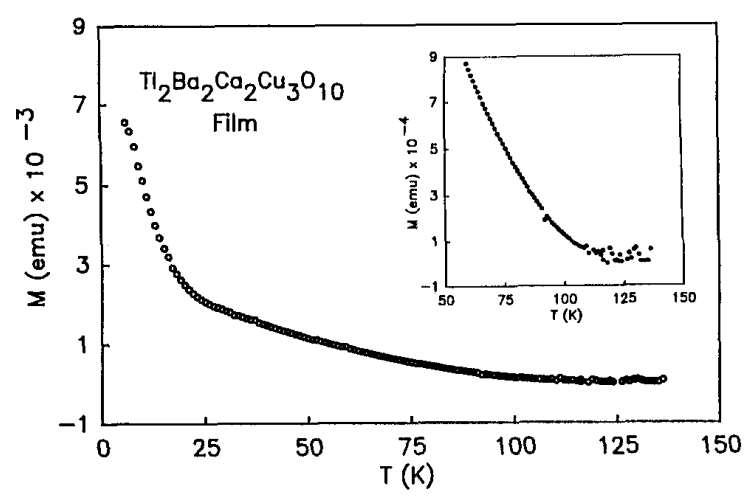

Fig. 7 Flux trapping versus temperature for the film annealed at $895^{\circ} \mathrm{C}$ for 1 hour. This data were obtained after cooling in the applied field of $50 \mathrm{kOe}$, removing the field and taking the data on warming in zero field.

\section{Summary}

Superconducting films of Tl-Ba-Ca-Cu-O have been prepared by sputtering. Films with zero resistance $\mathrm{T}_{\mathrm{c}}$ of up to $122 \mathrm{~K}$ were obtained after various post annealing at $870 \sim 895^{\circ} \mathrm{C}$ from 1 hour to 3 hours. The composition of films is not very homogenous in sub-micrometer scale. The critical current at $77 \mathrm{~K}$ of the these films are in the $10^{3} \mathrm{~A} / \mathrm{cm}^{2}$ to $10^{4} \mathrm{~A} / \mathrm{cm}^{2}$ range, which is much smaller than that of the films prepared on $\mathrm{SrTiO}_{3}$ and $\mathrm{LaAlO}_{3}$ substrates. The low critical current density in these films are likely due to the granularity in these films .
* This work is supported by NASA Lewis grant NAG 3-866, the Nebraska University Foundation and the Nebraska Energy Office.

\section{References}

1. Z.Z. Sheng and A.M. Hermann, Nature, 332, 138(1988).

2. R.M. Hazen, L.W. Finger, R.J. Angel, C.T. Prewitt, N.L. Ross, C.G. Hadidiacos, P.J. Heaney, D.R. Veblen, Z.Z. Sheng, A. El Ali, and A.M. Hermann, Phys. Rev. Lett., 60, 1657(1988).

3. C.C. Torardi, M.A. Subramanian, J.C. Calabrese, J. Gopalakrishnan, K.J. Morrissey, and T. Sleight, $S c i$ ence, 240, 631(1988).

4. S.S.P. Parkin, V.Y. Lee, E.M. Engler, A.I. Nazzal, T.C. Huang, G. Gorman, R. Savoy, and R. Beyers, Phys. Rev. Lett., 60, 2539(1988).

5. D.S. Ginley, J.F. Kwak, R.P. Hellmer, R.L. Baughmen. E.L. Venturini, and B. Morosin, Appl. Phys. Lett., 53. 406(1988).

6. Y. Ichikawa, H. Adachi, K. Setsune, S. Hatta, K. Hirochi, and K. Wasa, Appl. Phys. Lett., 53, 919(1988).

7. W.Y. Lee, V.Y. Lee, J. Salem, T.C. Huang, R. Savory, D.C. Bullock, and S.S.P. Parkin, Appl. Phys. Lett., 53 , 329(1988).

8. S.H. Liou, M. Hong, A.R. Kortan, J. Kwo, D.D. Bacon. C.H. Chen, R.C. Farrow, G.S. Grader, Proc. of the Conference on the Science and Technology of Thin Film Superconductors, Colorado Springs, Colorado 1988 edited by Robert D. McConnell and Stuart A. Wolf (Plenum, New York). p229.

9. S.H. Liou, Proc. of Material Research Society, Vol. 169 , (1990).

10. S.H. Liou, unpublished.

11. C.P. Bean, phys. Rev. Lett., 8, 250(1962).

12. S.S. Yom, T.S. Hahn, Y.H. Kim, H. Chu and S.S. Choi, Appl. Phys. Lett., 54, 2370(1989). 